\title{
Sarcoplasmic Reticulum
}

National Cancer Institute

\section{Source}

National Cancer Institute. Sarcoplasmic Reticulum. NCI Thesaurus. Code C33514.

The endoplasmic reticulum of striated muscle, specialised for the sequestration of

calcium ions that are released upon receipt of a signal relayed by the $T$ tubules from the neuromuscular junction. 